Eng. Sara Paganoni, Dr. Dina D’Ayala

\title{
Testing and Design Procedure for Corner Connections of Masonry Heritage Buildings Strengthened by Metallic Grouted Anchors
}

Eng. Sara Paganoni - PhD candidate

Dept. Architecture and Civil Engineering

University of Bath

Claverton Down

Bath, BA2 7AY

Mob. +4917676967247

S.Paganoni@bath.ac.uk

Dr. Dina D'Ayala - Reader

Department of Civil, Environmental and Geomatic Engineering

University College London

Chadwick Building, Gower Street

London, WC1E 6BT 


\begin{abstract}
Structural connections are crucial in determining the seismic behaviour of buildings; their importance is indeed acknowledged by current design codes, both in the case of new built and of heritage structures. Eurocode 8 in particular encourages the strengthening of connections of existing structures so as to ensure global response; yet, at the state of the art, clear prescriptions regarding the assessment of connections of heritage buildings and the design of appropriate strengthening systems are missing. Even the scientific literature seldom deals with the issue of connections, both in the unreinforced and strengthened set-up. As such, designers are left with the issue of experimentally characterise the capacity of connections, and of sourcing data and choosing suitable design procedures in order to comply with the requirements prescribed for retrofit interventions on historic buildings. In the attempt of tackling the lack of quantitative data, as well as of providing template for the experimental assessment and design of strengthening systems for connections, the authors carried out two sets of laboratory tests on masonry samples strengthened by metallic grouted anchors. Parameters significant to the performance of the connection are identified through experimental results and a design procedure is developed. The paper analyses in detail the response of a widely-applied strengthening technique, but also provides general guidance for dealing with the repair and strengthening of connections of heritage buildings.
\end{abstract}

Keywords: structural connections, heritage buildings, metallic anchors, repair and strengthening

\title{
1 Introduction
}

In the last decades, a number of technical solutions for the improvement of structural connections have been developed in response to the increasing demand for strengthening systems specifically designed for the seismic protection of heritage assets [1,2, and 3]. At the same time, the experimental assessment of strengthening techniques is a well-established practice both in the scientific community and among commercial producers.

It is therefore surprising that testing of connections as such is rarely performed, and very few codes of practice deal with this topic. Commercial strengthening techniques are generally designed and tested for the repair and upgrade of a single structural element $[4,5]$, or at the global scale on building prototypes [6,7]. Neither methodology specifically targets the performance of unstrengthened or strengthened connections; on the other hand, the few examples of experimental procedures $[3,8]$ devised to this purpose are not standardised or codified, and therefore hardly repeatable.

Design codes stress the importance of providing effective connections during the seismic retrofit and upgrade of heritages structures, so as to achieve a more favourable distribution of horizontal loads depending on the stiffness of structural elements $[9,10]$. Nevertheless, clear prescriptions for the design of strengthening systems are missing. In fact, end users are left with the difficult task of complying with code requirements with the only support of qualitative indications.

At the same time, recent post-earthquake reconnaissance campaigns [11, 12].provide clear evidence of the negative impact of poorly designed and badly installed strengthening systems The paper aims to address the technical gaps described above by describing the testing procedures developed and adopted within the framework of the EU-funded FP7NIKERproject (Grant Agreement No 244123, www.niker.eu) for the assessment of masonry specimens strengthened by metallic anchors.

Cross-ties have been widely implemented over the last centuries to restore the box-like behaviour of masonry structures in many historic city centres across Europe and the Mediterranean basin. Nowadays, metallic anchors are still commonly applied as they offer 
the advantage of scarcely increasing the mass of the structure, while preserving its integrity and global behaviour by reducing cracking phenomena. Yet, despite the improvement of installation techniques and the use of materials with better durability and performance, little research has been carried out on the performance of this strengthening system and the literature lacks design guidelines.

Therefore, two testing campaigns are carried out: the first consists of pull-out tests of grouted anchors from one element of a corner connection, namely the wall perpendicular to the seismic action. The purpose is to identify possible failure modes and the capacity of the strengthening assembly, both as a whole and as a system of components with different responses to axial loading. The second testing campaign is performed on T-shaped masonry specimens, so that the whole connection, two orthogonal walls and the strengthening element, can be studied. In this case the focus is on those factors that cannot be accounted for through pull-out tests: the effect of cyclic loading and the damage on the wall parallel to the seismic action.

Drawing on the experimental results and the technical literature, an analytical method for calculating the capacities of the various elements in the assembly is proposed and its suitability verified by comparing calculated values with those achieved experimentally. Hence, the objective of this work is not only to provide insight into the mechanics and failure modes of a widely-used strengthening technique, but also to propose a systematic and comprehensive testing and design methodology of general validity for anchorage systems in stone and brick masonry.

\section{Monotonic Pull-Out Tests}

The purpose of pull-out tests is to analyse the behaviour of a connection between two vertical elements, i.e. walls, strengthened by steel anchors. The focus is on the performance of the anchor, and the damage caused to the wall perpendicular to the anchoring direction by the monotonic action of pull-out.

Given the lack of specific design clauses for anchors in masonry substrata, for the sake of homogeneity with current codes of practice, the same protocols used for pull-out test of anchors in concrete substrata [13] and of masonry bed-joint reinforcement [14] are applied. However, greater attention is given to phenomena and requirements specific to historic masonry, such as the influence of a non-homogeneous substratum on the modes of failure and the importance of damage limitation.

The technology used for anchors is the CINTEC's system (C) [15], which comprises a stainless steel profile encased in a fabric sleeve that is installed in holes core-drilled in the structure and then injected by grout. The flexible sleeve of woven polyester restrains the grout flow and expands to about twice its initial diameter, moulding itself into the shape and spaces within the walls, providing mechanical as well as chemical bond. Therefore, the anchoring system relies on shear and mechanical locking for the transmission of load to the substratum; as no front plate is needed, the disruption to the architectural features is maintained to a minimum. Experimental campaigns are devised in light of the specific characteristics of the anchoring system, as explained in the following. 


\subsection{Test Set-Up}

The test set-up consists of a stainless steel anchor within a grouted socket bonded to a wall subject to the pulling action of the testing apparatus, which simulates the reaction of the anchor lying within the wall being subjected to acceleration normal to its plane, tending to cause overturning (Fig.1).

Since the test involves the presence of only one masonry panel, its application could also be implemented for the testing of anchors connecting vertical to horizontal elements (e.g. roof or floor timber rafters or joists connected to walls) when considering the performance of the anchor/wall interface.

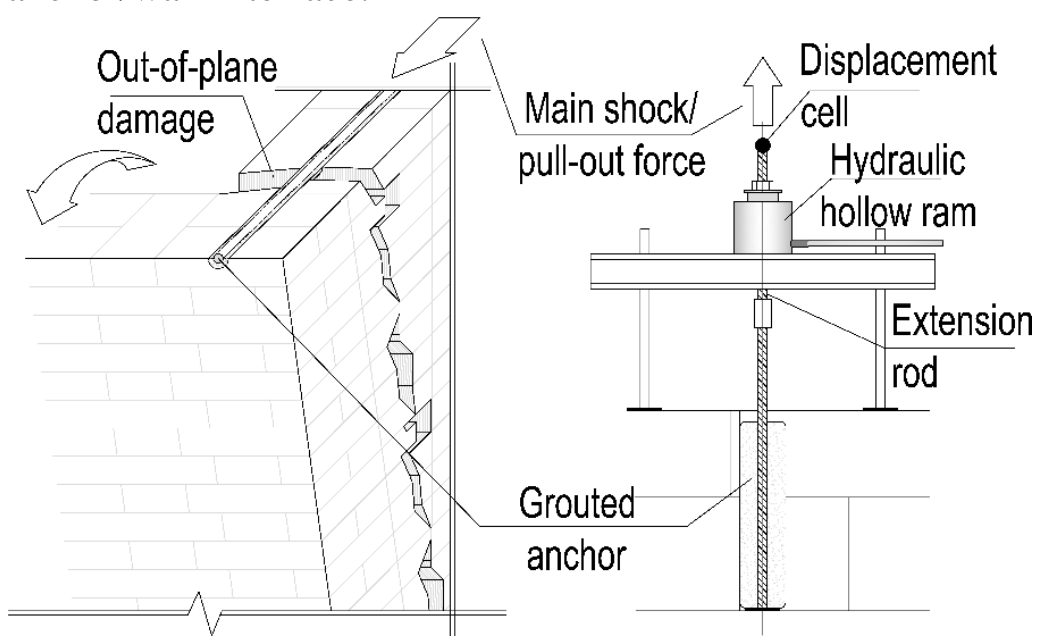

Fig.1 Lay-out of on-site application and lay-out of experimental simulation of cross tie

\subsection{Materials and Samples}

Following the prescriptions of [14] for testing of ancillary components of masonry, anchors are positioned in free-standing panels. The relative distance between anchors must be sufficient to avoid interaction effects between adjacent anchors or between anchor and wall edges. No prescription is given by design codes in this regards; the minimum distance of two diameters centre to centre that determines a group effect in the case of piles is taken instead as reference [16].

The positioning of the anchors in respect to bed joints, head joints and masonry units is intentionally left random, so that results can be representative of the average behaviour of anchors in an irregular substratum, although care is taken that at least one joint is included in the area of coring, so as to avoid performing a pull-out from a single brick.

A vertical load is applied throughout tests; the code [14] prescribes the use of a load apt to create a stress between 0.05 and $0.1 \mathrm{MPa}$, which simulates the typical compression stress field perpendicular to bed joints. In the tests two different values of loads are applied to three out of the six anchors, each group being installed in a different wall panel. The use of different levels of vertical compression allows for the analysis of the influence of the vertical load on the performance of anchors. A first panel undergoes a load creating a pressure of 0.07 $\mathrm{MPa}$, thus reproducing the standard case scenario according to code, whereas a pressure of $0.7 \mathrm{MPa}$ is applied to the second panel. The latter vertical load represents the limit case scenario of application of anchors installed in bell towers or buildings with heavy horizontal structures like vaults. 
Masonry panels are built using recycled Victorian bricks and natural hydraulic lime mortar (Fig.2a). Characterisation of materials is carried out according to relevant Eurocodes [17, 18, and 19]. The mechanical properties of materials at age of testing are summarised in Table 1, whilst the overall set-up in shown in Fig.2. The characteristics of tested anchors are reported in Table 2.

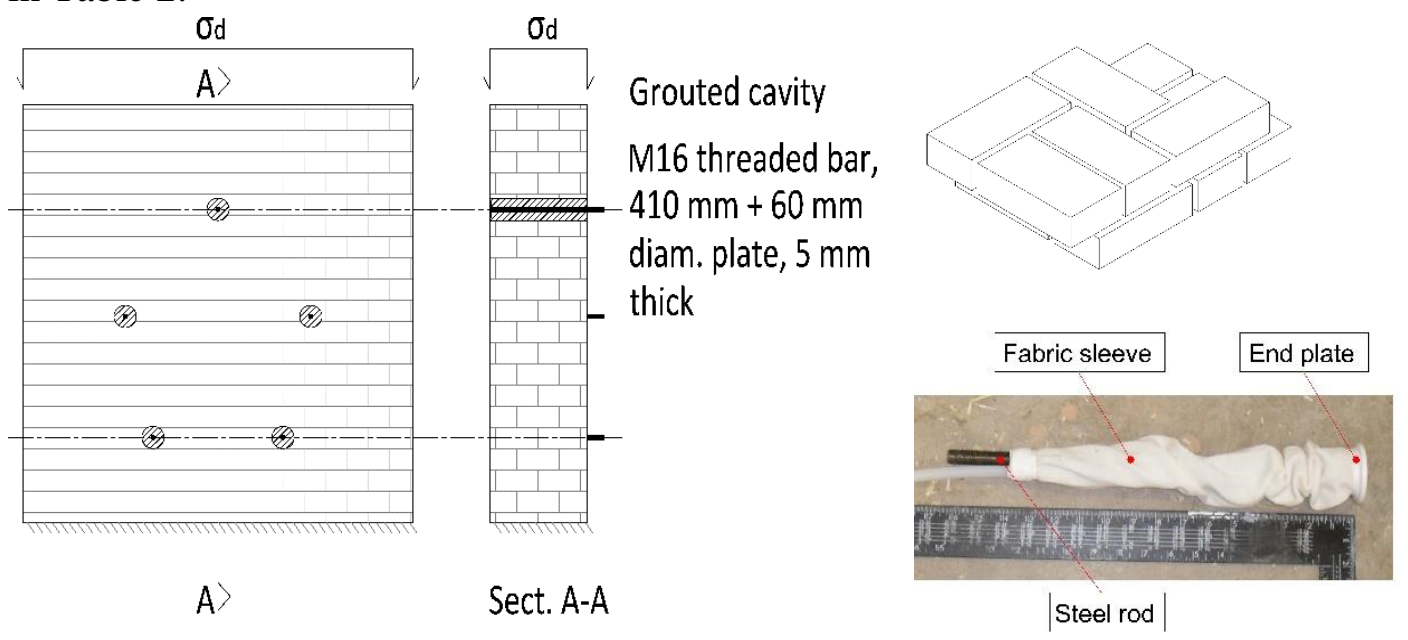

Fig.2 a) Set-up of masonry panels for pull-out tests; b) Detail of masonry units lay-out according to an English cross bond; c) Detail of anchor

Table 1: Mechanical properties of materials used for test samples

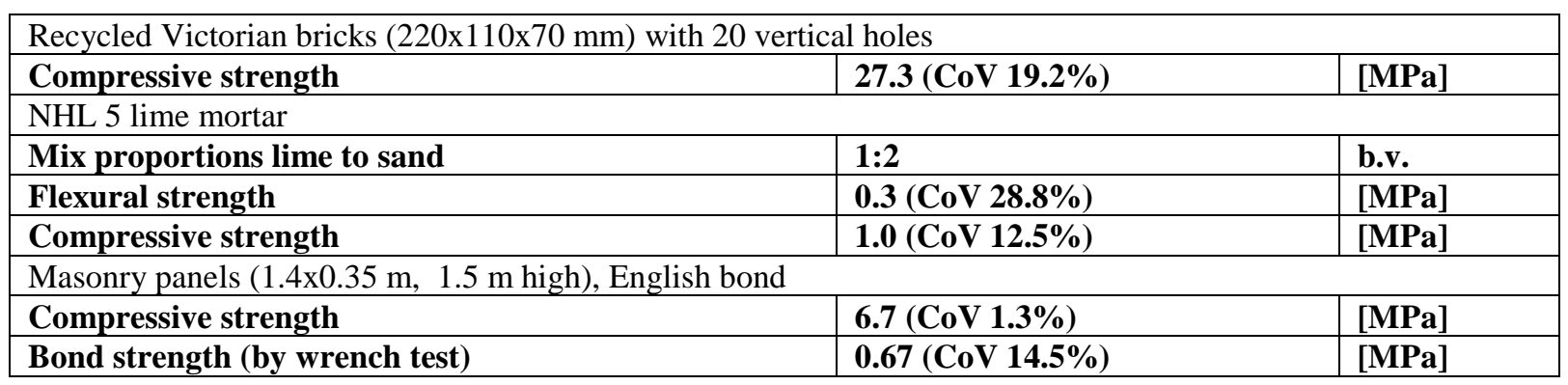

Table 2: Summary of the characteristics of the grouted anchors

\begin{tabular}{|l|l|l|l|}
\hline M16 bars, AISI 304 stainless steel (UNI 14301) class 70 \\
\hline Nominal diameter & 16 & $\mathrm{~mm}$ & \\
\hline Cross sectional area & 201 & $\mathrm{~mm}^{2}$ & \\
\hline Yield stress & 450 & $\mathrm{MPa}$ & $\begin{array}{l}\text { Minimum values taken from producer's data } \\
\text { sheet }\end{array}$ \\
\hline Ultimate tensile stress & 700 & $\mathrm{MPa}$ & \\
\hline Anchor rod length & 400 & $\mathrm{~mm}$ & \\
\hline Embedment length & 350 & $\mathrm{~mm}$ & Equal to wall thickness \\
\hline Rear plate diameter & 60 & $\mathrm{~mm}$ & \\
\hline Drilling hole diameter & 80 & $\mathrm{~mm}$ & \\
\hline Cementicious grout & 50 & $\mathrm{MPa}$ & As stated by the producer \\
\hline Grout compressive strength & 50 \\
\hline
\end{tabular}

It should be noted that the used grout is cement-based. Although the use of cement is generally detrimental in heritage structures due to its scarce compatibility with other historic material, the standard grout provided by the producers was still used for the tests. This is done in light of two main observations: the first is that the fabric sleeve encasing the anchor doesn't allow the grout to flow freely within the masonry, thus largely limiting the 
introduction of additional material in the structure. In the second place, it was decided to adopt a commercial system its whole, as normally applied in common practice, thus reflecting a typical strengthening system, as observed in historic centres.

\subsection{Testing Procedure and Instrumentation}

Tests are performed in load control mode, with pull-out load being applied by a hydraulic jack in steps of $2 \mathrm{kN}$. Load is increased, maintained constant for 1 minute and then increased again, so as to read the loss of load capacity, if any, between increments. Vertical load is kept constant throughout the test.

Total displacements are measured by the dial gauge located in series with the pulling apparatus (Fig.1), while relative displacements of the grouted sleeve and the parent material around the grouted hole are measured by displacement transducers.

At the end of the test the load is released down to $2 \mathrm{kN}$ to read the residual deformation. The test is considered complete when either the parent material presents damage, this being clearly detectable by visual inspection or by recorded measurements, or when the target displacement of $10 \mathrm{~mm}$ is reached. Limitation of damage to finishes, and hence to the substratum in general, is indeed a main requirement of strengthening systems for heritage structures and should therefore be accounted for during tests. The limit displacement criterion is set considering that a $10 \mathrm{~mm}$ displacement is comparable, yet lower, than the maximum allowable drift for damage limitation, $\mathrm{d}_{\mathrm{r}}=0.003$, taken from [20]; this standard, unlike [10], specifically refers to ordinary masonry buildings when stating drift limits for masonry walls and is therefore deemed more suitable in the case of historic masonry structures. The limit is also in line with the expected drift stated in [21] for unreinforced masonry buildings at the limit state of Immediate Occupancy. The limit drift is increased by the factor $v=0.4$, which is derived from [10] and applies to heritage structures, which fall in the importance category III of Eurocode 8 [10].

\subsection{Experimental Results}

Likely failure modes of grouted anchors can be predicted on the basis of the authors' experience, on-site observations and comparison with anchors embedded in concrete [22, 23]. In particular, for the testing set-up described above, failures might occur according to the modes listed in Table 3 and shown in Fig. 3.
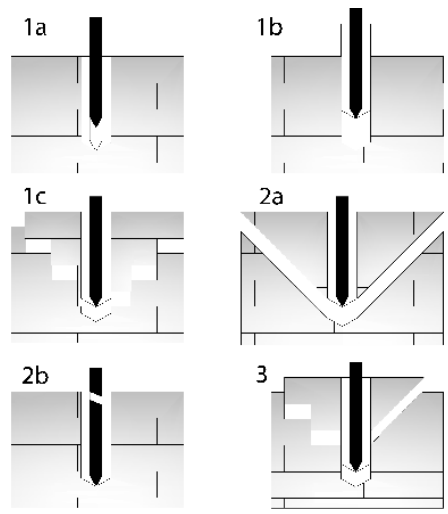

Fig. 3 Possible modes of failure of bonded anchor in masonry substratum undergoing tensile axial force

Table 3: Summary of possible failure modes of grouted anchors 


\begin{tabular}{|c|c|c|c|}
\hline \multicolumn{4}{|c|}{ Failure modes } \\
\hline \multirow[t]{3}{*}{1} & $\mathrm{a}$ & \multirow[t]{3}{*}{ Bond failure between } & steel profile and grout \\
\hline & $\mathrm{b}$ & & grouted element and parent material \\
\hline & $\mathrm{c}$ & & adjoining bricks \\
\hline \multirow[t]{3}{*}{2} & $\mathrm{a}$ & \multirow[t]{3}{*}{ Tensile failure of } & masonry units \\
\hline & $\mathrm{b}$ & & masonry mortar joints \\
\hline & $\mathrm{c}$ & & steel profile \\
\hline \multicolumn{2}{|l|}{3} & Mixed mode & Combination of others \\
\hline
\end{tabular}

Of these failures, types $1 \mathrm{a}$ and $2 \mathrm{c}$ rarely occur in practice, as:

- The crests of the anchor rod ensure a good bond between the metallic bar and the surrounding grout, as long as grouting is carried out according to the producers' recommendation. Additionally, the chosen typology of anchors features an end plate at the rear of the anchor rod, which prevents the pull-out of the bar by working in compression, thus shifting the failure to the grouting material [24].

- Steel normally has the highest ultimate capacity among the elements of the assembly, unless the steel profile is substantially under-dimensioned.

Such observations were taken in due consideration while devising the testing campaigns, so as to avoid unrealistic failures.

During tests, it is observed that the failure of the bond between the grouted sleeve and the parent material (type 1b) is the first to occur and the most common, then followed in some cases by a further increase in stiffness and cracking of other elements of the assembly according to other failure types (Fig. 4 and Fig. 5).
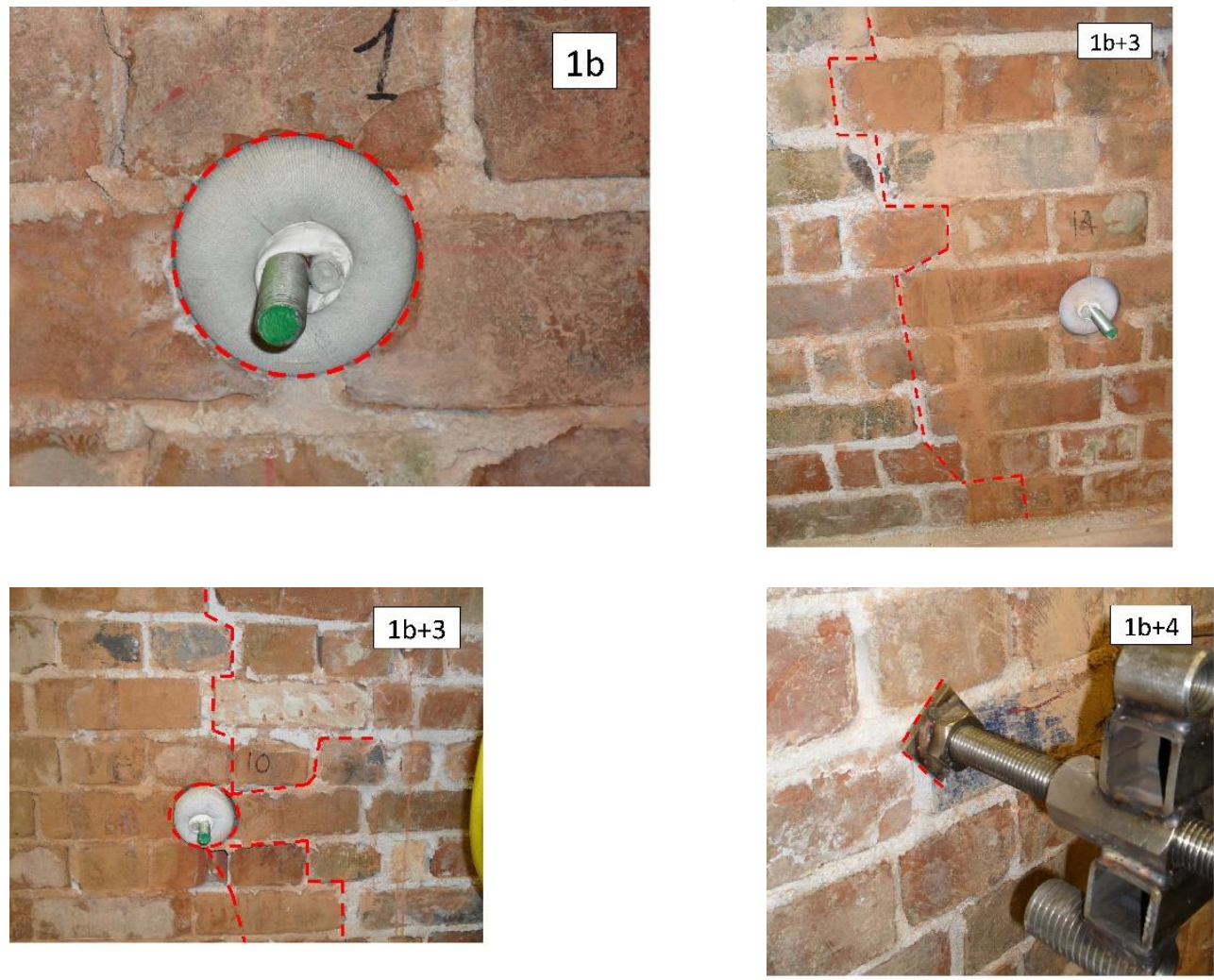

Fig. 4 Modes of failure observed during tests: bond failure (1b), followed by further locking and display of other failures such as bond failure in the mortar joints $(1 b+3)$ or crushing of masonry $(1 b+4)$ 
Failure types 1c, 2a and 3 determine, rather than a cone-shaped failure surface, pseudovertical cracks developing either in the head joints or in those bricks where the holes of the masonry units provide a weak pattern. This type of failure is likely to be caused by the mechanical locking of the anchors within the parent material. Whereas a homogeneous material would behave similarly to the idealised modes of failure shown in Figure 3, irregularities, which are typical of historic masonry, provoke high shear stresses, so that cracking randomly radiates from the hole to the parent material, thus affecting the shape of the failure surface.

Accidental crushing of masonry at the support of the pulling apparatus can also occur due to the test set-up (failure type No 4).

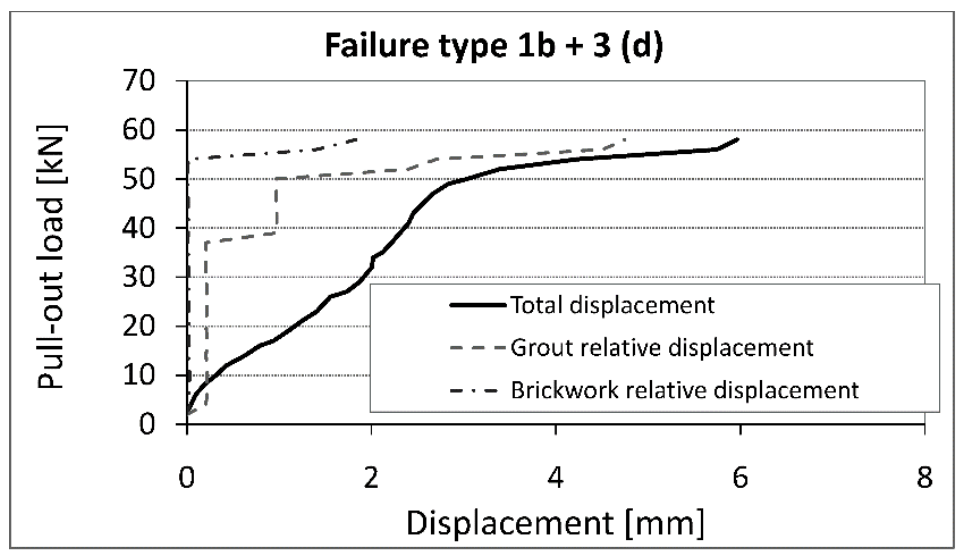

Fig. 5 Relative displacements within assembly of anchor showing how failure in the bond between grouted sleeve and parent material is the first to occur

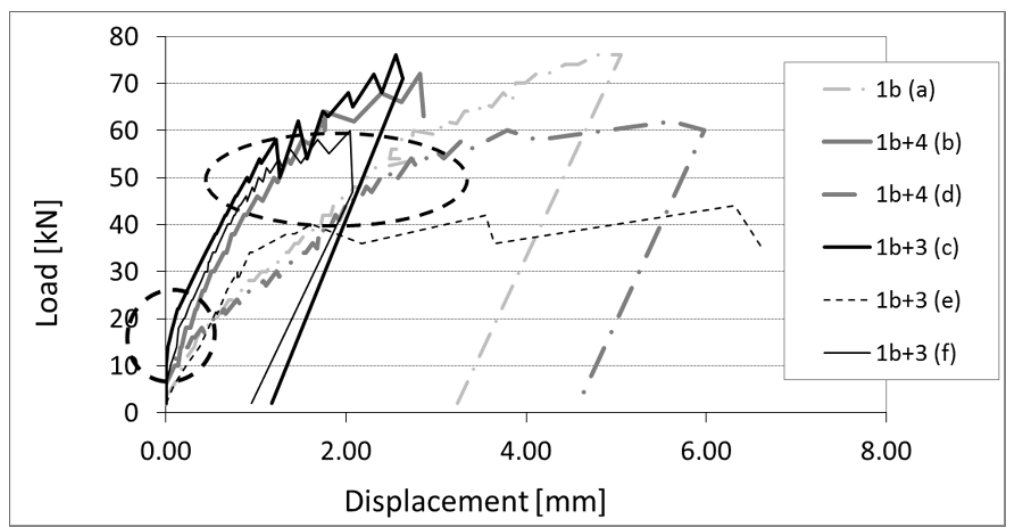

Fig. 6 Load-displacement graph of tested anchors. The legend indicates the failure mode and the labelling of anchor specimens, which is reported in brackets

Table 4: Summary of tested specimens and modes of failure as labelled in Fig. 6

\begin{tabular}{|l|l|l|}
\hline Sample No & Failure type \\
\hline $\mathrm{a}$ & $1 \mathrm{~b}$ & Bond failure grouted element/ parent material \\
\hline $\mathrm{b}$ & $1 \mathrm{~b}+4$ & $\begin{array}{l}\text { Bond failure grouted element/ parent material followed by failure due to testing } \\
\text { apparatus (masonry crushing at the pulling rig footing) }\end{array}$ \\
\hline $\mathrm{c}$ & $1 \mathrm{~b}+4$ & $\begin{array}{l}\text { Bond failure grouted element/ parent material followed by failure due to testing } \\
\text { apparatus (masonry crushing at the pulling rig footing) }\end{array}$ \\
\hline $\mathrm{d}$ & $1 \mathrm{~b}+3$ & Bond failure grouted element/ parent material followed by a mixed mode \\
\hline $\mathrm{e}$ & $1 \mathrm{~b}+3$ & Bond failure grouted element/ parent material followed by a mixed mode \\
\hline $\mathrm{f}$ & $1 \mathrm{~b}+3$ & Bond failure grouted element/ parent material followed by a mixed mode \\
\hline
\end{tabular}


For adhesion, a model similar to that proposed by [26] could be adopted:

$$
N_{u, m}=\tau_{0} \pi d_{0} h_{e f}
$$

where $\mathrm{d}_{0}$ and $\mathrm{h}_{\text {ef }}$ are respectively diameter and embedment length of the grouted anchor. The failure stress, $\tau_{0}$, is assumed uniform on the whole embedment length, as such simplification doesn't impair the correctness of the model [26].

Mechanical locking, which is unlikely in concrete, is influential in the case historic masonry and of the specific anchoring system, due to the presence of the fabric sock, the type of masonry and hence the roughness of the drilled cavity.

When mechanical locking occurs, the behaviour at interface grout/parent material of the tested anchors can be qualitatively assimilated to that of a threaded bar embedded in grout or concrete: the pull out force is resisted by friction as well as by the bearing of the irregularities of the grouted sock against the surrounding material, which reacts in compression. This assumption is justified by the fact that bond failure steel/grout, as already said, is prevented by the anchor rear plate.

However, the phenomenon of mechanical locking in a masonry substratum is far more scattered, as surface irregularities are not as uniform as the crests of a thread. This means that while locking can affect the performance of a single anchor, its favourable, yet unpredictable, effect should not be accounted for in an analytical model that represent the average performance of anchors.

Therefore, the shear strength of masonry is used as uniform failure load in equation (1) and as it is a standard value that can be easily calculated by codes and, in the case of historic masonry, it represents a lower bond in respect to the bond strength of grout to masonry.

Using the relationship proposed by [27] the bond strength measured by wrench tests during material characterisation can be related to a value of characteristic initial shear strength $f_{v k 0}$, equal to $0.24 \mathrm{MPa}$. Characteristic shear strength is [28]:

$$
f_{v k}=f_{v k 0}+0.4 \cdot \sigma_{d}
$$

where $\sigma_{\mathrm{d}}$ is the compressive applied stress perpendicular to bed joints, calculated taking into account both the dead loads and the applied vertical compression.

The pull-out capacity as calculated through equations (1) and (2) is summarised in Table 5: Values of shear strength and pull-out capacity as calculated or ; measured values are averagely $70 \%$ higher than those calculated, highlighting the relevance of interlocking strength.

\begin{tabular}{|c|c|c|c|c|}
\hline & & Calculated & & Measured \\
\hline $\begin{array}{l}\text { Anchor } \\
\text { No }\end{array}$ & $\begin{array}{l}\sigma_{\mathrm{d}} \\
{[\mathrm{MPa}]}\end{array}$ & $\begin{array}{l}\text { Shear strength at interface grouted } \\
\text { sock/masonry [MPa] - Eq (2) }\end{array}$ & $\begin{array}{l}\text { Pull-out capacity } \\
{[\mathrm{kN}]-\mathrm{Eq}(1)}\end{array}$ & $\begin{array}{l}\text { Pull-out capacity } \\
{[\mathrm{kN}]}\end{array}$ \\
\hline $\mathrm{a}$ & 0.707 & & & 60 \\
\hline $\mathrm{b}$ & 0.713 & 0.52 & 46.1 & 64 \\
\hline $\mathrm{c}$ & 0.713 & & & 54 \\
\hline $\mathrm{d}$ & 0.077 & 0.27 & 23.8 & 58 \\
\hline $\mathrm{e}$ & 0.091 & (2) & 243 & 40 \\
\hline $\mathrm{f}$ & 0.091 & 0.28 & 24.3 & 52 \\
\hline
\end{tabular}

Table 5: Values of shear strength and pull-out capacity as calculated or measured 

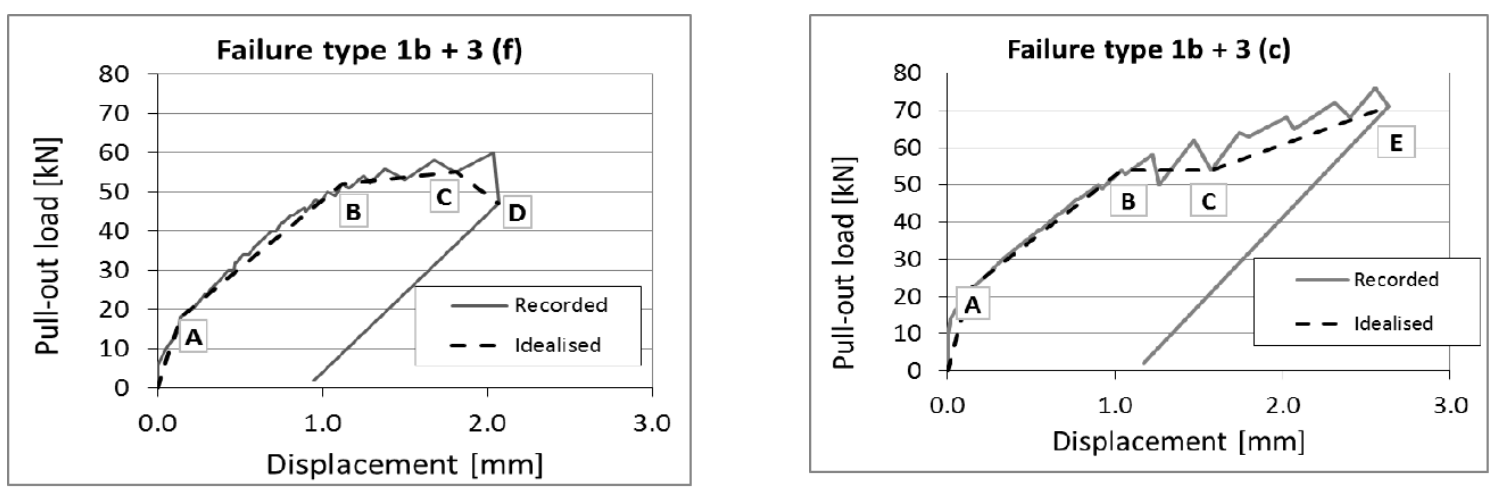

Fig.7 Idealised curves of recorded load-displacement curves showing the changes in stiffness

Looking in details at load-displacement curves, other aspects emerge. Each curve presents more than one change in stiffness, thus identifying: the first appearance of relative movement (point A), the achievement of maximum load (point B), the achievement of maximum displacement (point $\mathrm{C}$ ) and the ultimate failure (point D) (Fig.7a). In some cases, a further increase in stiffness is detected (point E) (Fig.7b).

The first change in stiffness can be identified with precision by looking at the relative displacements in the single components, in particular at the measurements recorded at the surface of grout and brick (Fig.8 and Table 6).

Whereas load values at points A are well below the pull-out capacity calculated on the basis of $\mathrm{f}_{\mathrm{vk}}$, a fair correlation is achieved by comparing them with the pull-out capacity calculated on the basis of $f_{\mathrm{vk}, 0}$, i.e. by neglecting the positive contribution of any vertical load (Table 6). It is therefore likely that point A represents a first micro-cracking at the interface between grout and parent material at the outer portion of the anchor, where the influence of the confinement of the surrounding material is lower. This is in line with the observations reported by [29], which indicate that bond strength is proportional to the level of lateral confinement.

The peak capacity is reached at point B. Load-displacement curves are not perfectly horizontal between point $\mathrm{B}$ and $\mathrm{C}$, thus meaning that the anchor still has a residual capacity due to friction and mechanical locking. This behaviour provides a certain measure of ductility at peak capacity, which makes this type of anchors particularly suitable for applications in seismic environments. Beyond point $\mathrm{C}$, load capacity eventually drops and the anchor reaches its ultimate capacity, unless further mechanical locking, arising while the anchor slides out of the cavity, allow for a further increase in stiffness (point E, Fig.7b).

It is worth highlighting, that anchors undergoing a higher vertical compression, namely anchors a, b and c, (Table 6) have averagely higher capacity, thus demonstrating the correctness of applying an analytical relationship that involves friction and perpendicular load. This also means that the contribution of the friction at the interface between grouted socket and parent material is prevalent in respect to mechanical locking for the development of the tensile capacity of the anchor assembly. Nevertheless, mechanical locking did occur in some cases, thus introducing scattering in the results, as it each anchor was affected in a different way depending on its geometry.

Overall, anchors achieve levels of maximum loads that are in line with, or even higher than calculated values, meaning that the adopted analytical model seems able to predict the load 
capacity, even if in a conservative manner. Anchors undergoing lower perpendicular pressure present more of a ductile behaviour, as the lower frictional forces on the failure surface allow for relative movements between the substratum and the grouted anchor. This is a desirable characteristic in case of strengthening of buildings located in seismic prone areas, even more so considering that the lower level of vertical pressure applied during tests is in fact an average working level in masonry construction and therefore a frequent case scenario.

Table 6: Summary of calculated pull-out loads and performance points as computed from recorded loaddisplacement curves of anchor assembly. Performance points are: A, first damage, B, maximum load, maximum displacement, $D$, ultimate failure and $E$, further attainment of stiffness.

\begin{tabular}{|c|c|c|c|c|c|c|c|c|c|c|c|c|c|}
\hline \multirow{3}{*}{$\begin{array}{l}\text { Anchor } \\
\text { No }\end{array}$} & \multirow{3}{*}{$\begin{array}{l}\sigma_{\mathrm{d}} \\
{[\mathrm{MPa}]}\end{array}$} & \multirow{3}{*}{$\begin{array}{l}\text { Pull-out } \\
\text { capacity } \\
\text { calculated } \\
\text { from } \mathbf{f}_{\mathrm{vk}, 0} \\
{[\mathrm{kN}]}\end{array}$} & \multirow{3}{*}{$\begin{array}{l}\text { Pull-out } \\
\text { capacity } \\
\text { calculated } \\
\text { from } \mathbf{f}_{\mathrm{vk}} \\
{[\mathrm{kN}]}\end{array}$} & \multicolumn{10}{|c|}{ Measured } \\
\hline & & & & \multicolumn{2}{|l|}{$\mathbf{A}$} & \multicolumn{2}{|l|}{ B } & \multicolumn{2}{|l|}{$\mathbf{C}$} & \multicolumn{2}{|l|}{ D } & \multicolumn{2}{|l|}{$\mathbf{E}$} \\
\hline & & & & $\mathbf{k N}$ & $\mathbf{m m}$ & $\mathbf{k N}$ & $\mathbf{m m}$ & $\mathbf{k N}$ & $\mathbf{m m}$ & $\mathbf{k N}$ & $\mathbf{m m}$ & $\mathbf{k N}$ & $\mathbf{m m}$ \\
\hline $\mathrm{a}$ & 0.707 & \multirow{6}{*}{21} & \multirow{3}{*}{46} & 16 & 0.34 & 60 & 2.75 & 66 & 3.84 & & & 76 & 5.05 \\
\hline $\mathrm{b}$ & 0.713 & & & 42 & 0.87 & 64 & 1.77 & 62 & 2.09 & 6 & 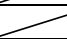 & 72 & 2.82 \\
\hline $\mathrm{c}$ & 0.713 & & & 22 & 0.13 & 54 & 1.04 & 54 & 1.57 & & & 71 & 2.63 \\
\hline$d$ & 0.077 & & 24 & 10 & 0.06 & 58 & 3.29 & 60 & 5.98 & - & - & & \\
\hline $\mathrm{e}$ & 0.091 & & \multirow{2}{*}{24} & 34 & 0.93 & 40 & 1.61 & 35 & 6.62 & - & - & & \\
\hline $\mathrm{f}$ & 0.091 & & & 18 & 0.14 & 52 & 1.12 & 55 & 1.81 & 47 & 2.07 & & 7 \\
\hline & & & Average & 24 & 0.41 & 55 & 1.93 & 55 & 3.65 & & & 73 & 3.5 \\
\hline & & & $\mathrm{CoV}(\%)$ & 51 & 95 & 15 & 47 & 47 & 61 & & & 4 & 38 \\
\hline
\end{tabular}

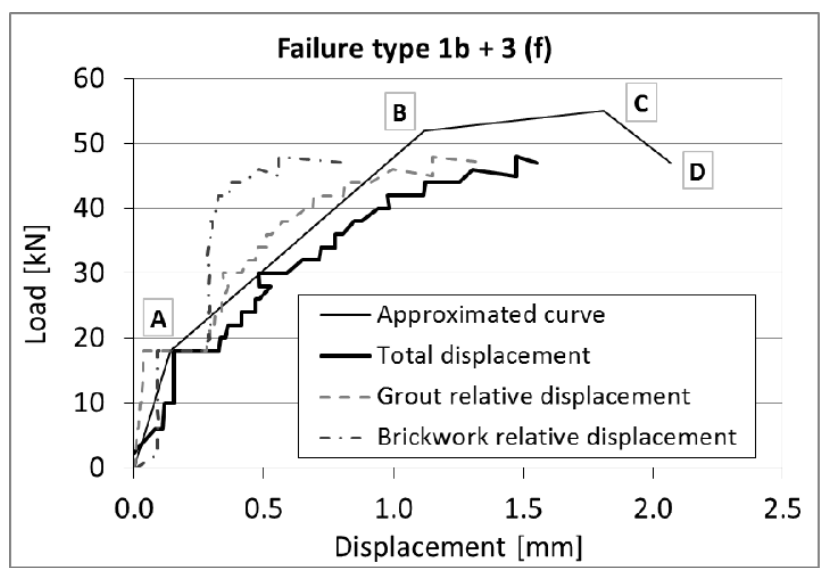

Fig.8 Comparison between idealised load-displacement curve of anchor assembly and curves showing relative displacements of various components

\section{Cyclic Tests on T-Shaped Walls}

Pull-out tests can be used to assess the capacity of metallic anchors undergoing monotonic load and determine the failure mode in the wall panel of the corner connection perpendicular to the seismic action. However, they are not representative of variable dynamic loading and of the interaction between walls.

Accordingly cyclic tests of a connection between two walls, strengthened by post-installed steel anchors, are carried out. A different type of bricks than pull-out tests is used for the construction of specimens, while the anchor technology is the same as described in $\$ 2.2$. 


\subsection{Test Set-Up}

Tests simulate the joint between two perpendicular walls connected by means of an anchor: samples are T shaped walls where the 'leg' of the T reproduces the wall parallel to the main seismic action, whereas the 'head' of the T represents a section of a panel undergoing out-ofplane rotation. The $\mathrm{T}$ leg is connected to a strong wall that simulates the rest of the building, whilst the $\mathrm{T}$ head undergoes cyclic loading that creates an overturning mechanism and the formation of a crack at the connection between the two walls (Fig.9). Such type of damage is recurring in historic buildings due to poor bonding length within the brickwork, this being recreated in the sample by ensuring a scarce overlapping of bricks at the joint.

The connection between the walls and the strong wall is ensured by post-installed anchors, one at the bottom, running along the $\mathrm{T}$ leg only, the other at the top of the wall, running throughout the head and the leg of the T. While the bottom anchor works purely as restraint, the top anchor is the object of testing and its lay-out is representative of standard applications. Indeed ties are generally installed at the top of buildings and the connection to the strong wall simulates the reaction force to pull-out load due to the bond between the parent material and the anchor, which runs along the whole specimen panel (Fig.10).

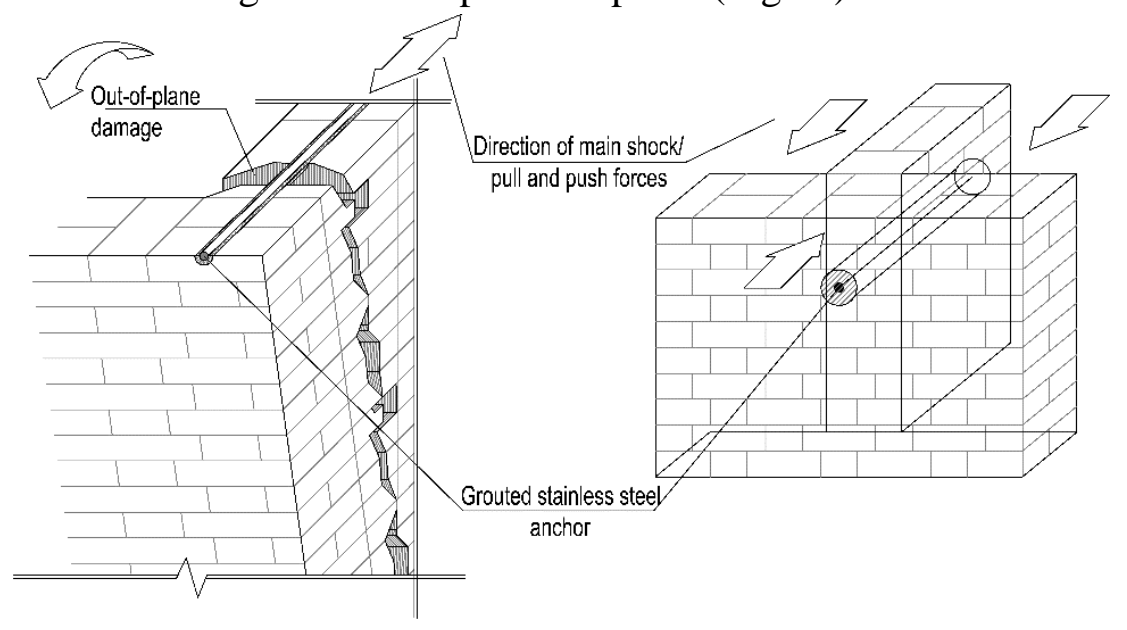

Fig.9 Layout of on-site application and layout of experimental simulation of cross tie at the joint between two perpendicular walls

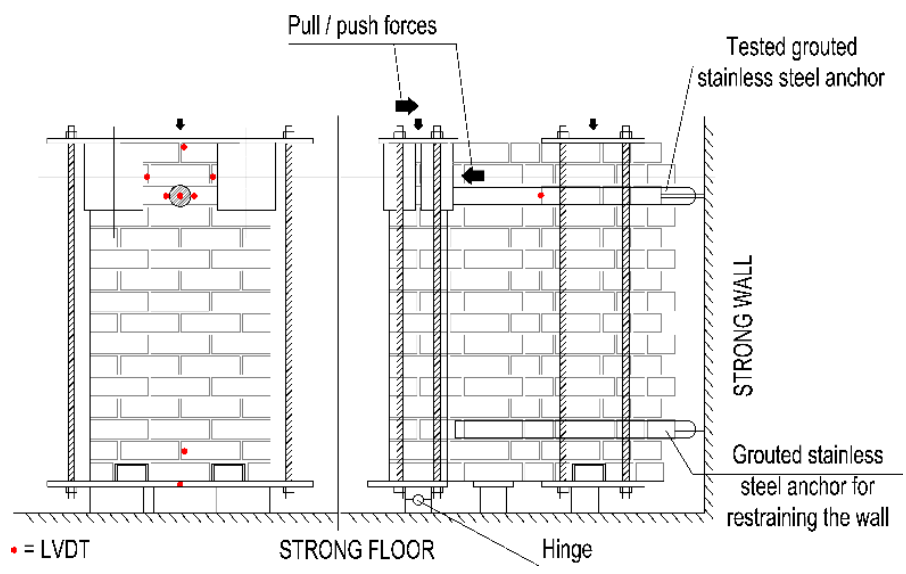

Fig.10 Test set-up 


\subsection{Materials and Samples}

A total of 4 walls are built; 3 are strengthened at the connections between the two panels by Cintec's standard anchors, whilst one is left unreinforced as control.

The walls are built in double bond, using recycled hand-cut bricks and natural hydraulic lime mortar. The head of the ' $\mathrm{T}$ ' is about $700 \mathrm{~mm}$ by $220 \mathrm{~mm}$ in plan, the leg is about $900 \mathrm{~mm}$ by 220 in plan; walls are $1200 \mathrm{~mm}$ high.

Characterisation of materials is carried out according to current codes, as per pull-out tests. Mechanical properties of material at the age of testing are summarised in Table 7. Anchors are made of the same profiles used for pull-out tests.

A vertical load representing the dead load of the upper structure is applied throughout the tests by steel plates compressed by tensioned threaded bars, which create a vertical stress field of approximately $0.08 \mathrm{MPa}$. Steel plates are used to spread the vertical load to the parent material (Fig.10 and Fig.11); this load is controlled by strain gauges placed on the vertical bars that measure deformation resulting from tensioning the rods by locking the hexagonal nuts at their top end.

Table 7: Summary of mechanical properties of test material resulting from characterisation tests

\begin{tabular}{|l|l|l|}
\hline \multicolumn{3}{|l|}{ Recycled hand-cut solid bricks (220x110x70 mm) } \\
\hline Compressive strength & $12.8(\operatorname{CoV} 13.5 \%)$ & {$[\mathrm{MPa}]$} \\
\hline NHL 5 lime mortar & $1: 2$ & b.v. \\
\hline Mix proportions lime to sand & $0.2(\operatorname{CoV} 19.3 \%)$ & {$[\mathrm{MPa}]$} \\
\hline Flexural strength & $0.5(\operatorname{CoV} 24.7 \%)$ & {$[\mathrm{MPa}]$} \\
\hline Compressive strength & $3.1(\operatorname{CoV} 16.0 \%)$ & {$[\mathrm{MPa}]$} \\
\hline T-shaped masonry walls, double bond & $0.50(\operatorname{CoV} 19.6 \%)$ & {$[\mathrm{MPa}]$} \\
\hline Compressive strength &
\end{tabular}

\subsection{Testing Procedure}

Cyclic load is applied by two hydraulic push jacks and one hydraulic pull jack restrained against the strong wall.

Tests are carried out in displacement control; the control point being at the level of the top anchor, at the midpoint of the front wall. Three cycles of loading and unloading are performed for increasing amplitude of displacement up to $10 \mathrm{~mm}$ of displacement or until visible damage occur, according to the same criteria set for pull-out tests.

Displacements are recorded at various levels (Fig.10) so as to observe the displacement profile and the evolution of damage along the height of the front of each sample. Additionally relative displacements occurring on the leg of the $\mathrm{T}$ are manually recorded every three cycles of load by relying on a reference grid, so as to detect the formation of diagonal cracks in the wall parallel to the direction of application of the cyclic load. 


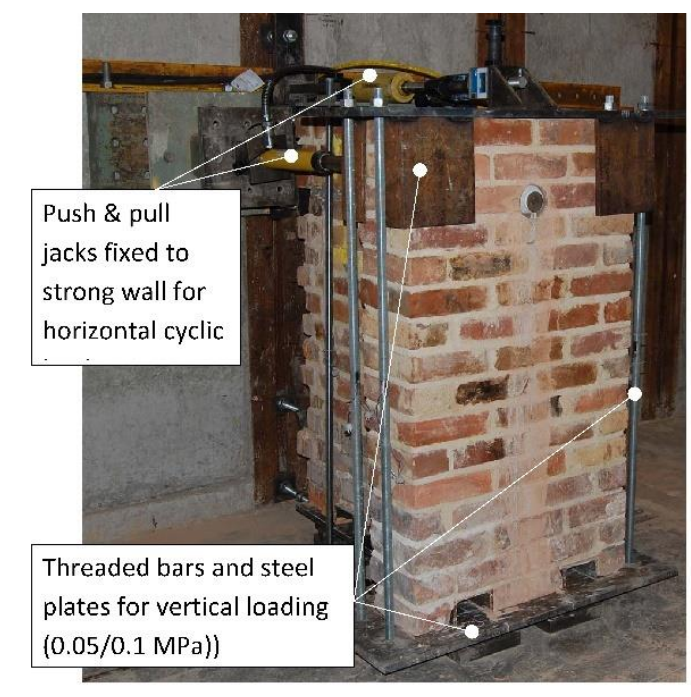

Fig.11 Set-up of $\mathbf{T}$ wall

\subsection{Results}

For the test set-up described above, failure is expected to occur initially by sub diagonal inplane cracking of the restrained wall parallel to the pull-push action, and eventually by failure of the head of the anchorage according to one of the failure modes described in the previous section (Fig.12).

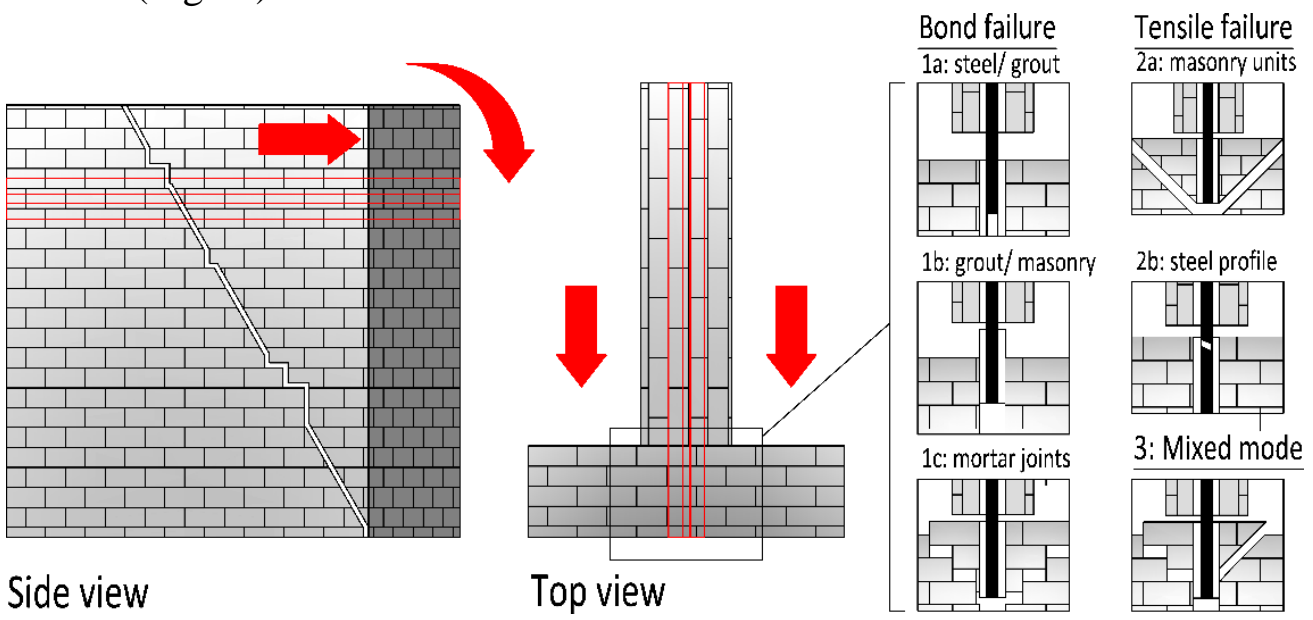

Fig.12 Expected mode of failure of T-shaped walls: a) initial formation of diagonal crack, followed by failure of the head of the anchorage according to one of the failure modes of (b)

Due to the use of different recycled materials and differences in the construction quality of samples, which depended on the availability of workmanship and materials at the time of construction, specimens developed lower mechanical properties in respect to pull-out tests. For instance, the use of smooth bricks, rather than bricks with holes, reduced the bond strength. Nevertheless, specimens are representative of low-quality masonry according to [20]; indeed values reported in Table 7 are comparable to poorly dressed masonry or roughlyhewn block masonry $\left(\mathrm{f}_{\mathrm{c}}=2.0 / 3.8 \mathrm{MPa}, \tau_{0}=0.035 / 0.074 \mathrm{MPa}\right)$.

As consequence of the poor mechanical properties of masonry, the bond between the grouted sleeve of the strength-only anchor in the front walls and the parent material fails at very early stages of tests. This is detected looking at the displacements at the level of the anchor: values recorded on the brickwork surface are proportional to the applied displacements; conversely, 
very little motion is detected on the metallic front plate of the anchor (Fig.13). Bond failure is also identified by plotting the displacements at different level of the front wall for each set of three load cycles with the same amplitude (Fig.14).

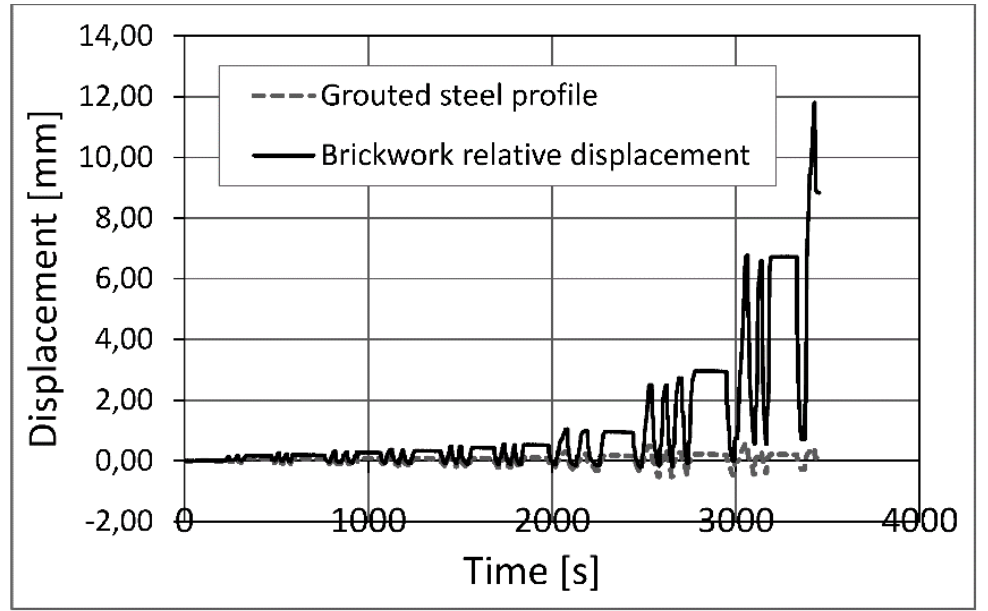

Fig.13 Displacements at anchorage level as recoded on brickwork surface and front end of grouted anchor

Because of this early failure, load is not transmitted to the rear wall by the anchor and diagonal in-plane cracking doesn't occur. Instead, a vertical crack opens at the joint between the two parts of the walls following the weak pattern provided during the preparation of specimens by leaving the bricks at the joint with a smaller overlapping. This reflects the fact that, if the anchor is not able to develop a sufficient bond, its effectiveness in reconnecting two walls is reduced, as it could be expected.
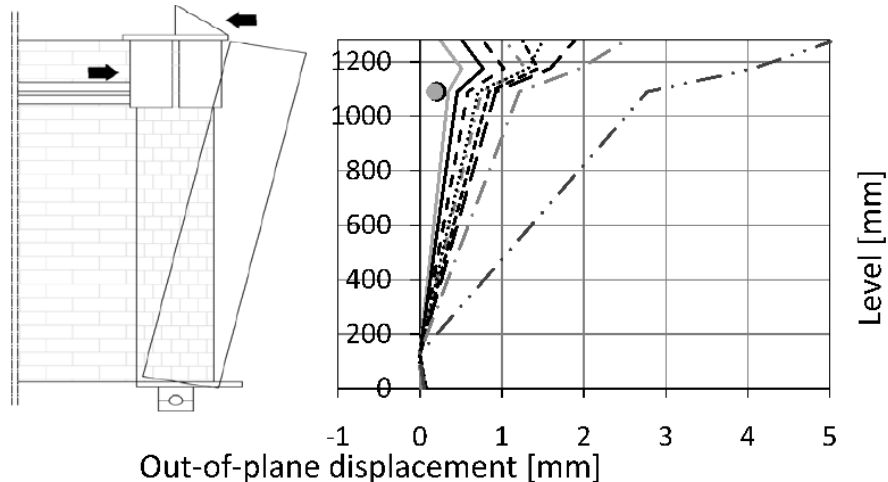

Fig.14 Displacement profiles along the whole height of the front wall. Differently dashed profiles indicate displacements at different amplitudes of applied displacement cycles; the position of the anchor is marked as a dot

The failure of the head of the anchorage in the front wall follows the mode already described for pull-out tests (summary in Table 8): an initial bond failure at the interface between the grouted sleeve and the parent material is followed by a "wrench" failure (Fig.15a). The formation of cracks in the front wall shows that, even after the failure of the bond, the assembly still transmits a punching action to the head of the T via mechanical locking. The phenomenon of locking can be observed once specimens are dismantled after testing (Fig.16): the grouted sock is indeed shaped according to the voids present in the masonry fabric. 

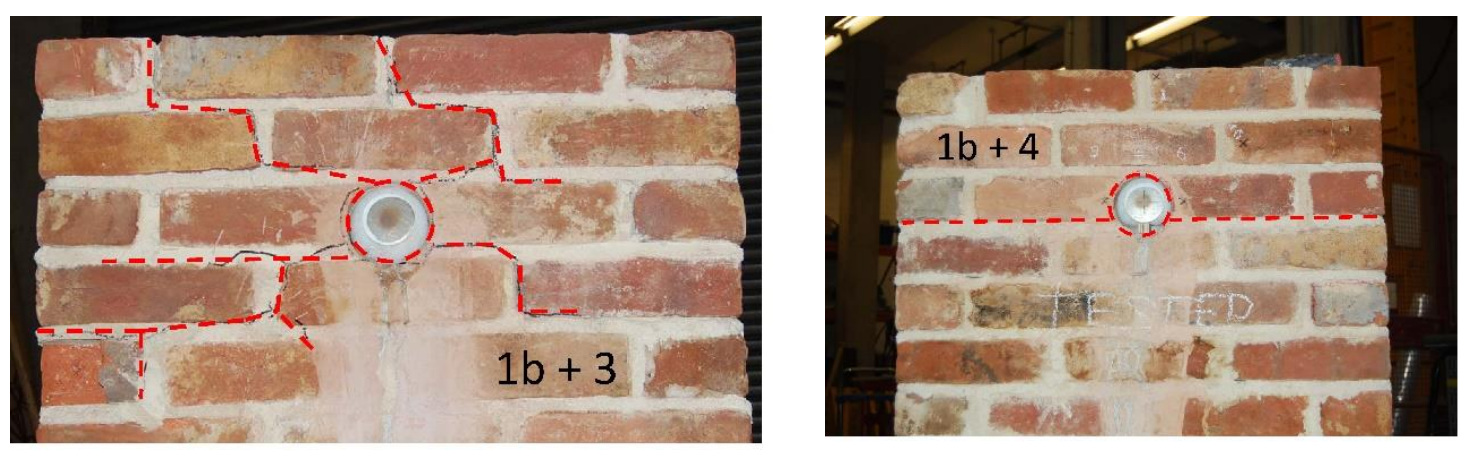

Fig.15 Failures of $\mathrm{T}$-shaped walls strengthened by grouted anchors: $1 \mathrm{~b}+3$ ) bond failure at grout/masonry interface followed by wrench failure (samples $2 \mathrm{~T}$ and 3T); 1b + 4) bond failure at grout/masonry interface + sliding shear mechanism resulting from the testing apparatus (sample 1T)

Table 8: Summary of the modes of failures observed during cyclic tests

\begin{tabular}{|l|l|l|}
\hline Sample No & Failure type \\
\hline $1 \mathrm{~T}$ & $1 \mathrm{~b}+4$ & $\begin{array}{l}\text { Bond failure grouted element/ parent material followed by failure due to testing } \\
\text { apparatus (sliding shear along bed joint of one course of bricks) }\end{array}$ \\
\hline $2 \mathrm{~T}$ & $1 \mathrm{~b}+3$ & Bond failure grouted element/ parent material followed by a mixed mode \\
\hline $3 \mathrm{~T}$ & $1 \mathrm{~b}+3$ & Bond failure grouted element/ parent material followed by a mixed mode \\
\hline
\end{tabular}

Due to the testing set-up and to the weakness of the bond mortar/masonry units, a sliding shear failure occurred in one of the specimens (Failure type No 4, see Fig.15b).

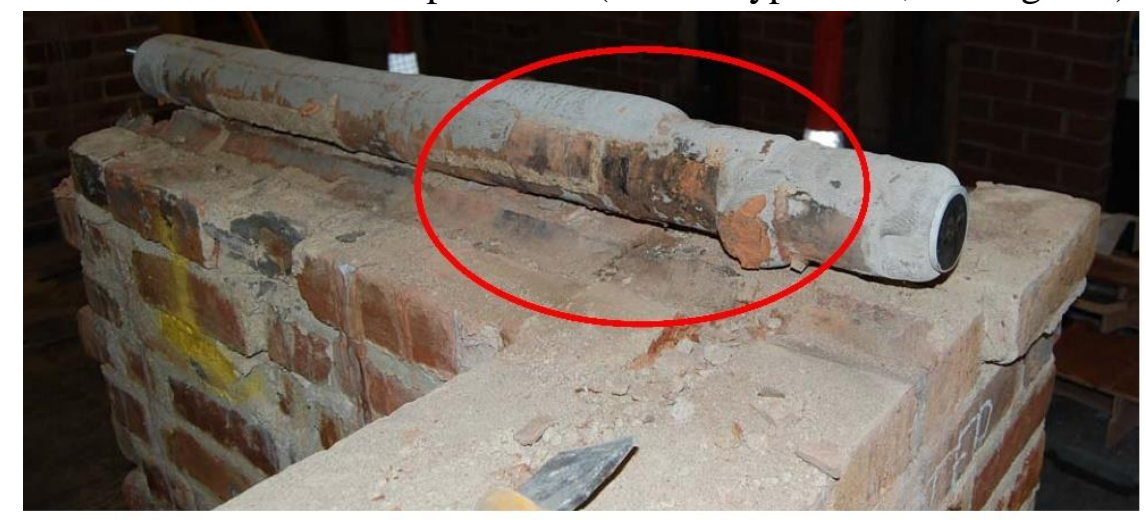

Fig.16 Shape of grouted sock as visible after testing and dismantling of masonry sample

This allows deriving the shear strength of the masonry directly from the tests, rather than using a value of shear strength borrowed from the literature. The force level that causes the activation of the shear sliding mechanism in the front wall (shown in Figure 15a) is detected by looking at the displacement profile of Fig.13b. Such force is divided by the area in plan of the head of the $\mathrm{T}$; this identifies $\mathrm{f}_{\mathrm{vk}}$, namely the shear strength that includes the effect of the vertical load applied on the head of the T. By reversing formula (2), the initial shear strength, $\mathrm{f}_{\mathrm{vk}, 0}$, can be calculated. Such value is then used to compute $\mathrm{f}_{\mathrm{vk}}$ for each wall, on the basis of $\sigma_{\mathrm{d}}$, the vertical load that was continuously recorded during tests.

The expected pull-out capacity is calculated considering the cylindrical surface of the portion of grouted anchor embedded in the front wall. Calculated results (Table 9) are averagely three times greater than calculated values. This is due to the fact that the performance of anchors is not only influenced by the friction at the interfaces of the assembly, but also by the bond and 
mechanical locking that the anchor is able to develop within the parent material. When the shear strength of the masonry is particularly low, these effects become prevalent and the use of the equation (2) can lead to underestimate the anchor load capacity.

Similarly to the process followed for pull-out test results, performance points can be identified by looking at the load-displacement cycles of samples, thus defining an idealised curve (Fig. 17 and Table 10). In the graphs, negative values of load correspond to the outward tilting movement of the front wall; positive values are instead recorded when the wall is moved back to the original position. An extra amount of force is needed to push the wall back to the " 0 displacement" position due to the presence of debris within the crack and local dislocations of bricks, which prevents the complete closure of the crack.

Table 9: Values of shear strength and pull-out capacity as calculated or measured

\begin{tabular}{|l|l|l|l|}
\cline { 2 - 4 } \multicolumn{1}{c|}{} & Calculated & Measured \\
\hline Sample No & $\begin{array}{l}\text { Shear strength at interface grouted } \\
\text { sock/masonry [MPa] }\end{array}$ & $\begin{array}{l}\text { Pull-out capacity } \\
{[\mathbf{k N}]-\text { Eq (1) }}\end{array}$ & Pull-out capacity [kN] \\
\hline $1 \mathrm{~T}$ & 0.08 & 4.435 & 10.9 \\
\hline $2 \mathrm{~T}$ & 0.06 & 3.329 & 17.8 \\
\hline $3 \mathrm{~T}$ & 0.06 & 21.9 \\
\hline
\end{tabular}

a)

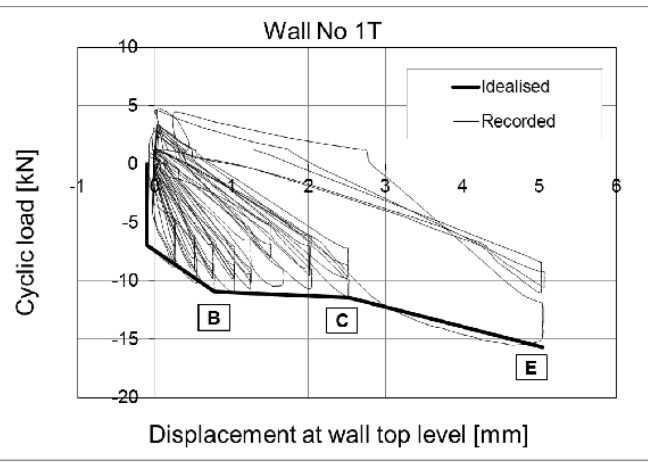

c)

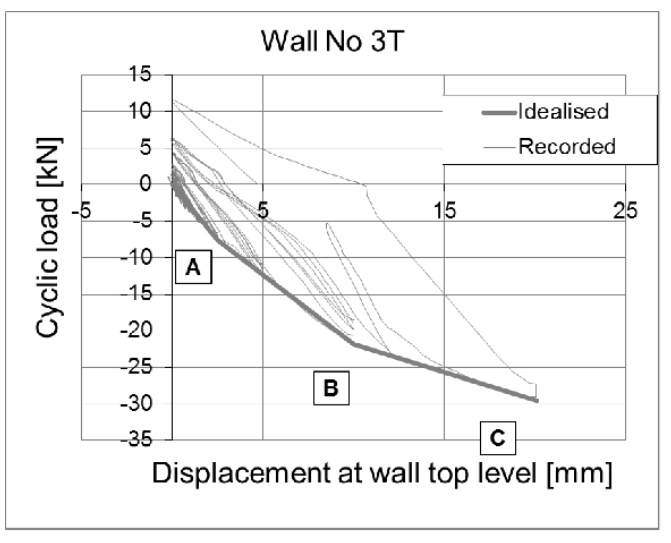

b)

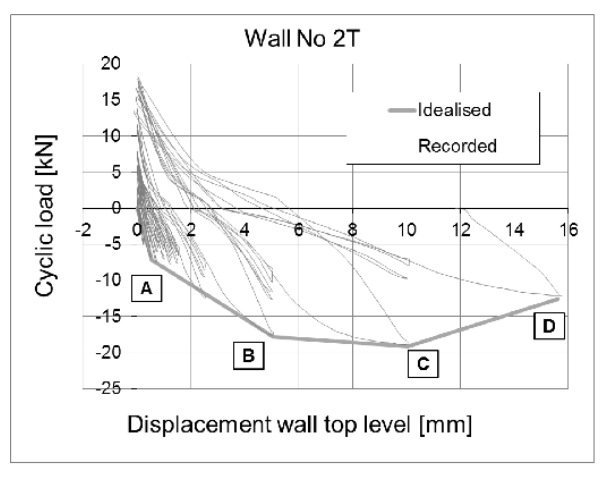

Fig. 17 Recorded and idealised load-displacement curves of tested walls: a) sample No 1T: grout/masonry bond failure of anchor and shear sliding failure of wall, b-c) samples No 2T and 3T: grout/masonry bond failure of anchor and wrench failure of wall

Performance points are defined as: A, first damage, B, maximum load, C, maximum displacement and $\mathrm{D}$, ultimate failure. In one case a further increase of stiffness (point E) occurs after the plateau between point B and C; it is also worth noticing that in all the cases the plateau is not perfectly horizontal, thus indicating a residual capacity in the joint after point $\mathrm{B}$, which can be conservatively considered as peak capacity. Importantly, even for such poor material characteristics of the substratum it is possible to identify a ductile behaviour of 
the assembly. Ductility is displayed during the first cycle of the suite at constant amplitude; the following two involve lower maximum load and almost linear cycles. The loss of load capacity as consequence of the reversal of load and of repeated is the natural consequence of the wearing of the surfaces along which friction occurs.

Table 10: Summary of calculated pull-out loads and performance points as computed from recorded load-displacement curves of anchor assembly

\begin{tabular}{|c|c|c|c|c|c|c|c|c|c|c|c|c|}
\hline \multirow{3}{*}{$\begin{array}{l}\text { Anchor } \\
\text { No }\end{array}$} & \multirow{3}{*}{$\begin{array}{l}\text { Pull-out capacity } \\
\text { calculated from } \\
\text { fvk, } 0[\mathrm{kN}]\end{array}$} & \multirow{3}{*}{$\begin{array}{l}\text { Pull-out capacity } \\
\text { calculated from } \\
\text { fvk }[\mathrm{kN}]\end{array}$} & \multicolumn{10}{|c|}{ Measured } \\
\hline & & & \multicolumn{2}{|c|}{ A } & \multicolumn{2}{|l|}{ B } & \multicolumn{2}{|l|}{$\mathbf{C}$} & \multicolumn{2}{|l|}{ D } & \multicolumn{2}{|l|}{$\mathbf{E}$} \\
\hline & & & $\mathbf{k N}$ & $\mathbf{m m}$ & $\mathbf{k N}$ & $\mathbf{m m}$ & kN & $\mathbf{m m}$ & kN & $\mathbf{m m}$ & kN & $\mathrm{mm}$ \\
\hline $1 \mathrm{~T}$ & \multirow{3}{*}{2.224} & \multirow{2}{*}{4.435} & 6.9 & 0.10 & 10.9 & 0.78 & 11.4 & 2.52 & & & 15.7 & 5.04 \\
\hline $2 \mathrm{~T}$ & & & 7.1 & 0.54 & 17.8 & 5.06 & 19.1 & 10.0 & 12.6 & 15.6 & & \\
\hline $3 \mathrm{~T}$ & & 3.329 & 7.6 & 2.52 & 21.9 & 10.0 & 29.6 & 20.1 & & & & \\
\hline & & Average & 7.2 & 1.05 & 16.9 & 5.28 & 20.0 & 10.9 & & & & \\
\hline & & $\mathrm{CoV}(\%)$ & 5 & 122 & 33 & 87 & 46 & 81 & & & & \\
\hline
\end{tabular}

Due to the early bond failure of the anchors, the overall behaviour of the specimens is highly influenced by the frictional force arising in response to the pulling action on the walls: friction is distributed on the bed joints along the vertical crack at the connection between the leg and the head of the T. Nevertheless, the presence of the anchor still positively influences the behaviour of the connection in respect to the unreinforced scenario (see comparison in Fig.18), partly thanks to the presence of the further friction surface at the interface between anchor and parent material, where the bond failure occurs, and partly because of mechanical locking, as mentioned before. Average load capacity of the strengthened samples is $17 \mathrm{kN}$, against the $4 \mathrm{kN}$ of the unreinforced sample.

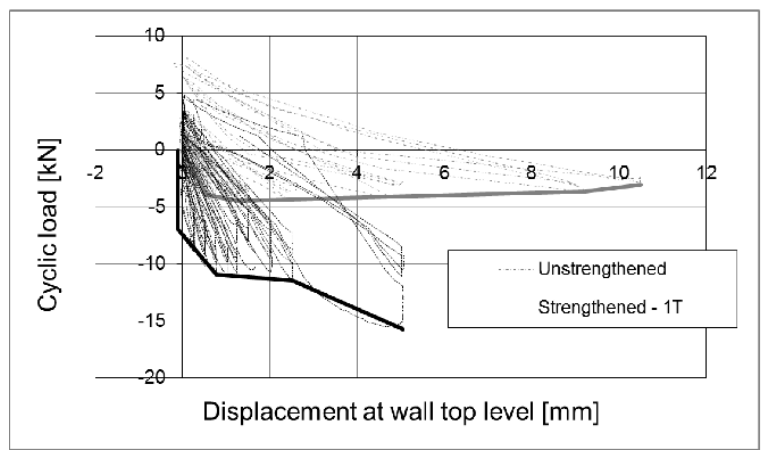

Fig.18 Recorded and idealised load-displacement curves of the unreinforced specimen and of wall No 1T - strengthened by grouted anchor 


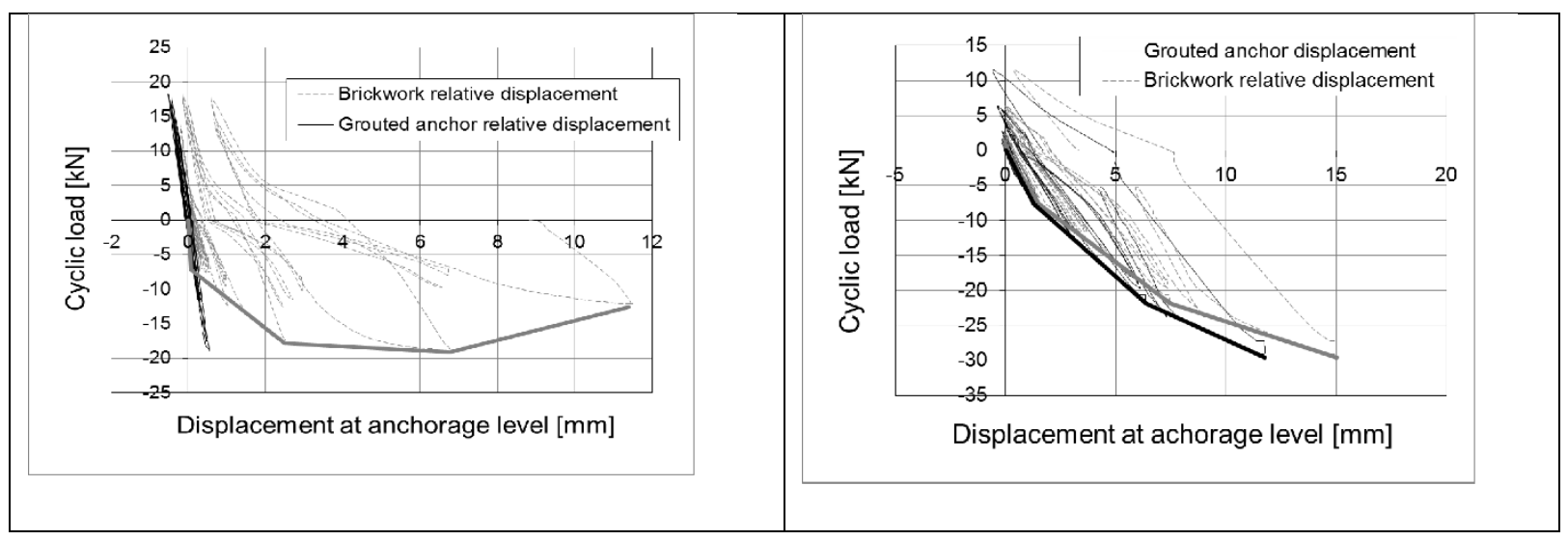

Fig.19 Recorded and idealised load-displacement curves of grouted anchors and parent material. a) Wall No 2T and b) wall No 3T

The improvement in the response of strengthened specimens in respect to the unreinforced one can be measured by computing the dissipated energy as the surface contained under the load-displacement loops. For strengthened specimens, such surface is averagely $140 \%$ larger than for the unreinforced specimen.

The way anchors influence the overall response of specimens is highly variable, as it can be observed by looking at the load-displacement curves of the grouted anchors in respect to those of the surrounding parent material (Fig.19). Whereas in some cases (Fig.19a) the bond failure occurs so early in the test that the two curves diverge immediately, in others (Fig.19b) a better bond is achieved; when this happens the specimen displays a higher capacity.

For specimens where a good bond between grout and masonry is developed, the performance points of the idealised curve are the same as for curves derived from pull-out tests: A is indeed the point where first damage occurs, after which the anchor is still able to contribute to the achievement of the maximum load capacity by maintaining a bond with the masonry (Fig.19b). If this is not the case, like in Fig.19a, the damage occurring at point A is sufficient to provoke an almost independent behaviour between the anchor and the front wall. The maximum load capacity recorded at point $\mathrm{B}$ is hence is influenced by the friction occurring at the joint between the two walls, where cracks open, and on the failure surface of the grouted anchor. As the sock moulds into the voids that are present within the wall, its surface can be highly irregular, thus providing a good contribution in terms of resisting force, especially when irregularities are of a size sufficient to create mechanical locking. Conversely, if the anchor is effectively embedded in the walls, the resisting action within the connection is ensured by the metallic element.

The punching effect of the surface irregularities of the grouted socket provokes a series of radial cracks that propagate from the initial failure surface at the interface grout/brickwork to the surrounding parent material. This behaviour is observed in cyclic tests as much as in some of the pull-out tests. The presence of "wrench" cracks indicates that the reaction of sock irregularities bearing in compression against the parent material is sufficient to stop relative motion and trigger a different resisting mechanism. The crack pattern depends on the geometry of the sample and it is hardly predictable; however, to the purpose of modelling and calculating the failure, it is sufficient to know the overall extent of the failure surface associated to this type of failure, rather than its exact geometry. Therefore, assuming that the 
failure mechanism is triggered when the strain energy stored in the metallic bar undergoing the axial load equates the fracture energy of the parent material, it is possible to calculate the crack surface area and verify whether theoretical results match the experimental evidence.

Table 11 shows the failure areas; the elastic strain energy is calculated only considering the strain of the metallic element, as it can be assumed that the strain energy stored in the masonry is negligible and it is released when the anchorage fails by cylindrical pull-out. As the maximum loads achieved during tests are lower than the yielding threshold of the metallic bars, the linear strain energy density can be written as:

$$
\int_{0}^{\varepsilon} \sigma_{s} d \varepsilon=\int_{0}^{\varepsilon}\left(E_{s} \varepsilon_{s}\right) d \varepsilon=\frac{1}{2} E_{s} \varepsilon_{s}^{2}
$$

where all the parameters in equation (3) refer to the steel bar.

For uniaxial loading, the linear strain energy per unit length becomes:

$$
U_{s}=\int_{A} \frac{1}{2} E_{s} \varepsilon_{s, x x}^{2} d A=\int_{A} \frac{1}{2} E_{s}\left(\frac{d u}{d x}\right)^{2} d A=\frac{1}{2} E_{s} A_{s}\left(\frac{d u}{d x}\right)^{2}=\frac{1}{2} \frac{N^{2}}{E_{s} A_{s}}
$$

Where the Young modulus and cross sectional area are again those of the threaded metallic bar. $\mathrm{N}$ is the axial load acting on the anchor at the moment of the punching failure, which is assumed to be completely resisted by the bearing mechanism of the grout irregularities, as the bond capacity has already been overcome and frictional forces are negligible, while slippage is prevented by mechanical locking.

The fracture energy per unit area of parent material surface is derived by the experimental results by [30]. Masonry specimens tested in tension perpendicularly to bed joints generally fail at the interface mortar/masonry units, this being the weakest element; therefore, the reported values of $f_{t}$ can be assimilated to the values of bond strength determined by wrench tests. Accordingly, a linear regression of the values of fracture energy reported by [30] is created in function of the tensile strength of masonry specimens, so as to calculate plausible values for the masonry typologies used for pull-out and cyclic tests (Table 11).

The total length of cracks on the outer surface of the wall is determined by dividing the failure surface area by the wall thickness. The extent of damage is clear by looking at the equivalent radius that approximates the damaged area in the hypothesis that cracks spread within a circular area. As masonry is not a homogeneous material and cracks will preferably spread along the mortar joints, which are normally the weakest element, the equivalent radius is calculated by dividing the number of bricks involved in the failure by the average number of bricks per masonry square metre. This is done to take into account the layout of masonry blocks. The value of the equivalent radius remains fairly constant across the set of specimens (Table 11) and could therefore be used as input for an analytical model, although this should be further investigated over a larger number of specimens, with different geometry and material properties, and by referring to more specific values of fracture energy.

Table 11: Failure surface generated by punching failure of the anchor assembly 


\begin{tabular}{|l|l|l|l|l|l|l|l|}
\hline & $\mathbf{f}$ & $\mathbf{U}, \mathbf{w}$ & Strain energy & $\begin{array}{l}\text { Failure } \\
\text { surface }\end{array}$ & $\begin{array}{l}\text { Cracks total } \\
\text { length }\end{array}$ & $\begin{array}{l}\text { No } \\
\text { bricks }\end{array}$ & $\begin{array}{l}\text { Equivalent } \\
\text { radius }\end{array}$ \\
\hline & {$[\mathbf{M P a}]$} & {$\left[\mathbf{N m m} / \mathbf{m m}^{2}\right]$} & {$[\mathbf{N m m} / \mathbf{m m}]$} & {$\left[\mathbf{m}^{2}\right]$} & {$[\mathbf{m}]$} & {$[-]$} & {$[\mathbf{m}]$} \\
\hline \multirow{2}{*}{$\begin{array}{l}\text { Pull-out } \\
\text { tests }\end{array}$} & 0.67 & 0.02 & 76.45 & 1.41 & 4.0 & 14 & 0.25 \\
\cline { 4 - 8 } & & 29.36 & 0.54 & 1.5 & 5 & 0.15 \\
\cline { 3 - 8 } $\begin{array}{l}\text { Cyclic } \\
\text { tests }\end{array}$ & 0.5 & 0.01 & 20.88 & 0.84 & 2.4 & 8 & 0.19 \\
\cline { 3 - 8 } & & 13.25 & 0.34 & 1.5 & 5 & 0.16 \\
\hline
\end{tabular}

Despite the difference in behaviour that derives from the quality and degree of bond and locking between anchor and parent material, the strengthening system succeeds in improving the performance of the connection. This is a main achievement, especially considering the weakness of the unreinforced specimen. Results suggest that control procedures should be implemented so as to ensure that the drilled hole presents sufficient irregularities to develop an effective bond and performance is less affected by the peculiarity of the local geometry of the hole. This would be particularly important in substrata where shear strength is low and a strong bond is unlikely to develop.

\section{Design Procedure by Experimental Results}

By performing pull-out and cyclic tests according to the indications provided above, one can derive a set of parameters that describe the performance of the unreinforced/strengthened connection, of its components and of the strengthening elements. Results presented herein are specific to a certain anchoring system and masonry typology and therefore not exhaustive of the complex variety of current strengthening systems and substrata. Nevertheless, they provide quantitative data, thus complementing the existing, scarce technical literature.

Furthermore, they highlight some interesting aspects of the strengthening of corner connections that could be further investigate by applying the same testing procedure to a larger numbers of specimens. Indeed, the paper mainly aims to describe the procedure whereby testing of connections can be performed; similarly, the proposed analytical model, although valid in the light of the experimental evidence reported here, would need further validation, should the equations become part of the standard procedure for the design of anchors.

As such, the work reported herein provides guidance for further experimental and analytical investigations and addresses the issue of how recorded parameters can then be turned into a procedure for dimensioning the strengthening system for design applications in real cases.

As discussed in the introduction, very little guidance is given regarding design procedures: both EC8 [10] and the Italian guidelines [9], which specifically addresses the retrofit of heritages structures, only suggest a number of techniques that are generally recognized as suitable in case of historic structures, but clear guidance of how these should be designed is not given.

To the purpose of addressing such technical gap, the authors developed a dimensioning procedure based on the idea that a connection system can be divided into sub-components to which one type of failure controlled by a single parameter can be associated. The whole set of 
these parameters determines the global response of the system, as each identifies a capacity and can be correlated to an analytical model, hence allowing the dimensioning of the connection system according to a hierarchical process of components' failure.

Individual components and system capacities can be calculated through the formulae prescribed by design codes. Input values can be obtained by bespoke laboratory and/or onsite tests or via other sources, such as producers' specifications and recommended or limit values provided by standards and guidelines.

The list of both experimental and prescribed values, as well as of formulae for the calculation of the components' capacities is thoroughly presented in a previous publication [31], whereas in the following the procedure for the implementation of such formulae in the design practice is described and summarised through the flow chart of Fig. 20.In addition to the 2013 publication and in the light of the positive influence of the anchor rear plate in respect to the load capacity for bar/grout pull-out, a further check has been added by considering the grout compressive capacity as stated by the producer and the bearing area defined as the net area of the plate bearing against the back of the grouted sock.

Design demand in terms of tensile force on metallic anchors is calculated as:

$$
F_{D}=M \cdot a_{i}
$$

Where:

$M$ : mass of structure that bears on the $\mathrm{i}^{\text {th }}$ anchor of the strengthening system. It depends on the geometry and construction arrangement of the building, including horizontal structures, and on the lay-out of the set of the anchors;

$\mathrm{a}_{\mathrm{i}}$ : horizontal peak acceleration experienced by the mass M. An estimate of the natural period of the system can be used to determine the correct design spectral ordinate and the distribution of amplification over the height of the structure, using standard response spectra or spectra derived from microzonation studies [32].

The sub-components are dimensioned in terms of strength for Significant Damage (also referred to as Life Safety) limit state, namely for the acceleration calculated for a seismic action with a probability of exceedance of $10 \%$ in 50 years [10].

$$
\left\{\begin{array}{l}
F_{\text {steel }} \geq F_{D, S D} \\
F_{a / b, b o n d} \vee F_{b . c o m p r} \geq F_{D, S D} \\
F_{b / p, \text { bond }} \geq F_{D, S D} \\
F_{\text {masonry }} \geq F_{D, S D}
\end{array}\right.
$$

The conditions expressed by equation (6) can also be written as:

$$
F_{B} \geq F_{D, S D}
$$


Where $F_{B}$ is the maximum load capacity of the overall anchor assembly, i.e. the load at point $\mathrm{B}$ of the idealised load displacement curves as derived from tests.

Current codes also provide for Near Collapse limit state (2\% probability of exceedance in 50 years); the dimensioning of point $\mathrm{B}$ of the anchor assembly according to this threshold is advised against, as requirements are stringent and would either lead to over-dimensioned anchors or result in unfeasible designs. However, some of the tested samples reach a point of maximum displacement, $\mathrm{C}$, and others are even able to develop further stiffness, up to point $\mathrm{E}$, this suggesting that anchors could also be designed for the ultimate limit state. Unfortunately, the anchors' response is scattered, this being the reason for not relying upon any performance point after B for design at Life Safety in the first place. Furthermore, the load increase between point B and $\mathrm{C}$ is averagely equal to 3\%for pull-out tests and to $16 \%$ for cyclic tests, this not being sufficient to withstand a severe earthquake. Conversely, the increase between $\mathrm{C}$ and $\mathrm{E}$ is roughly equal to the $40 \%$ for both pull-out tests and the one case of cyclic test when point $\mathrm{E}$ was reached; unfortunately, not all the tested anchors display point E. Therefore, it is suggested that further investigations of specific treatments of the surface between grout and parent material are undertaken to achieve homogeneous load response of the anchors and allow fully exploiting their load capacity.

[22] suggests an additional check in terms of strength of the assembly: the yielding load of the steel element needs to be lower than all the other failure loads associated to the concrete substratum by a factor of 0.6. Such equation is suggested to ensure the ductility of anchors in seismic prone areas. However, the design deriving from such requirement might be counterproductive: indeed, the bond capacity between the steel bar and the substratum decreases after yielding as a consequence of the Poisson effect, as discussed by [33] on the basis of several authors' research work. This is not a problem for the tested type of anchors, as the bearing mechanism of the rear plate, if properly designed, is sufficient to prevent the steel from sliding out of the grouted cavity.

Nevertheless, if the equation suggested by [22] was applied to masonry anchors, it would lead to extremely small sized steel elements in respect to the rest of the assembly. Whereas in concrete maximum loads for substratum failures have values comparable with steel yielding load, this is not the case for an anchor in a masonry substratum, where loads associated to failures of the parent material are several orders of magnitude smaller than steel yielding.

Therefore, the formula is instead written as:

$$
0.6 \cdot F_{b, \text { compr }} \geq F_{\text {steel }}
$$

By complying with equation (8) one ensures that the bearing mechanism of the rear plate can prevent the sliding of the metallic bar from the grouted socket even in case of yielding of the anchor rod.

Additionally, one needs to ensure that cracking of the anchor assembly is reduced in case of frequent seismic events, so that continuous occupancy can be guaranteed. Therefore, the design load at the limit state of Damage Limitation (probability of exceedance of $20 \%$ in 50 years according to [10]) should be lower than the anchors capacity at the point of first cracking, A. 


$$
F_{A} \geq F_{D, D L}
$$

For Damage Limitation, anchors should also comply with requirements imposed on interstorey drift. The chosen value of maximum allowable drift, $\mathrm{d}_{\mathrm{r}}=0.003$, is taken from [19] and [20], according to the conditions on damage limitations already expressed in $§ 0$.

It is therefore:

$$
d_{r}=d_{U D}+\Delta_{A} \leq 0.003 \cdot h / v=0.003 \cdot(3000 \mathrm{~mm}) / 0.4=22.5 \mathrm{~mm}
$$

where:

$\mathrm{d}_{\mathrm{UD}}$ : interstorey drift of the building in its undamaged configuration, i.e. before cracking of corner connections occurs. Indeed it is assumed that anchors, designed according to the discussed procedure, are able to prevent any major cracking, thus justifying the assumption of undamaged configuration. However, while calculating $d_{U D}$, one must account for the higher stiffness of the structure as consequence of anchors in respect to the unreinforced configuration.

$\Delta_{\mathrm{A}}$ : the displacement recorded in the anchors at point $\mathrm{A}$, first damage, in the idealised performance curves. $\Delta_{\mathrm{A}}$ represents the relative displacement of the panel perpendicular to the seismic action in respect to the other walls as far as permitted by the anchor at the limit state of damage limitation.

h: interstorey height, or vertical distance of installation of anchors. A standard distance of 3 meters has been assumed in the calculations, but anchors might need to be spaced more closely on the height of the wall to prevent substratum failures.

Ideally the sizing of a strengthening element for seismic protection should be mainly driven by requirements expressed in terms of displacement, rather than rely on a capacity design, as done above. However, anchors present a highly scattered performance, as it can be seen by calculating the ductility as the ratio between displacements at point $\mathrm{B} / \mathrm{C}$ and point $\mathrm{A}$ (Table 12). Therefore, similarly to the case of load capacity at NC limit state, the variability in performance prevents the full exploitation of the anchors' potential, unless a system to remedy such pitfall was designed and implemented.

Table 12: Ductility of standard anchors

\begin{tabular}{|l|l|l|l|l|}
\hline & \multicolumn{2}{|l|}{ Point B } & Point C \\
\hline Type of test & Average & Standard deviation & Average & Standard deviation \\
\hline Pull-out & 5.57 & 3.37 & 9.16 & 47.9 \\
\hline Cyclic & 7.05 & 2.78 & 17.25 & 8.69 \\
\hline
\end{tabular}

A hierarchical sequence for the overall design procedure is given in the diagram of Fig. 20, which shows the iterative process that should be followed when sizing an anchor for a specific case study and set the priority to constrain the design. 


\section{Conclusions}

The paper aims to tackle the lack of code prescriptions and literature references for the experimental assessment of structural connections of heritage structures and for the design of bespoken strengthening systems. To this purpose, the authors carried out two experimental campaigns on masonry corner connections strengthened by metallic grouted anchors within the framework of the FP7 NIKER project. Experimental results prove that the implemented testing procedures are suitable to determine the most recurring failure modes by looking at the relative displacements occurring in the assembly parent material/strengthening elements and to draw performance curves that identify main performance thresholds, such as: first damage, maximum load, and maximum displacement before loss of capacity and eventual failure.

Apart from providing quantitative data, which at the moment are missing from the technical literature, and further insight into a strengthening technique that is widely applied in current practice, but little studied, the description of the test set-up and measurements provides guidance for the assessment of structural connections that is generally applicable to other strengthening systems. By doing so, one could further substantiate the trends highlighted in this paper, so as to developed a comprehensive database and a proper standard for testing. Furthermore, experimental results are implemented in a design procedure whereby a complex strengthening systems is broken down into components and correlated to simple analytical models that are used to calculated the capacity of each component of the strengthened connection and hence the hierarchy of failure and overall capacity of the assembly parts.

The procedure refers to code prescriptions so as to make sure that the design falls in line with current requirements for structural systems and is comparable with the range of values that might be provided by codes. Far from exhausting the complexity of historic substrata and strengthening system, the design procedure can offer guidance for the further analysis of anchoring systems and for the development of similar procedures applied to different strengthening techniques, thus offering the opportunity of addressing the technical gap regarding the design of strengthening for connections.

\section{References}

[1] Borri A., Castori G., Grazini A. (2009). Retrofitting of Masonry Building with Reinforced Masonry RingBeam. Construction and Building Materials, 23(5):1892-1901.

[2] Di Croce M., Ponzo F. C., Dolce M. (2010). Design of the Seismic Upgrading of the Tambour of the S. Nicola Church in Catania with the DIS-CAM System. VII International Seminar on Structural Analysis of Historical Constructions - SAHC10, Shanghai, China.

[3] Indirli M., Castellano M.G. (2008). Shape Memory Alloy Device for the Structural Improvement of Masonry Heritage Structures. International Journal of Architectural Heritage, 2:93-119.

[4] Aiello M.A., Micelli F., Luca Valente L. (2007). Structural Upgrading of Masonry Columns by Using Composite Reinforcements. Journal of Composites for Construction, 11(6):650-658. 
[5] Borri A., Castori G., Grazini A., Giannantoni A. (2007). Performance of Masonry Elements Strengthened with Steel Reinforced Grout. Fibre-Reinforced Polymer Reinforcement for Concrete Structures - FRPRCS-8, Patras, Greece, 16-18 July.

[6] Dowling D., Samali B., Li J. (2005). An Improved Means of Reinforcing Adobe Walls- External Vertical Reinforcement. SismoAdobe 2005, Lima, Peru.

[7] Tomaževič M., Lutman M., Weiss P. (1996). Seismic Upgrading of Old Brick-Masonry Urban Houses: Tying of Walls by Steel Ties. Earthquake Spectra, 12(3):599-622.

[8] Al Shawa O., Bellisario M., Benedetti S., de Felice G., Mauro A., Paolacci F., Nicola R., Roselli I., Sorrentino L. (2009). Prove sperimentali su tavola vibrante di pareti murarie sollecitate fuori piano. ReLuis, progetto di ricerca n.1 (in Italian).

[9] DPCM (2011) Direttiva del Presidente del Consiglio dei Ministri 9 febbraio 2011. Valutazione e riduzione del rischio sismico del patrimonio culturale con riferimento alle Norme tecniche per le costruzioni di cui al D.M. 14/01/2008. Official Bulletin no. 47, 26/06/2011 (in Italian). Gazzetta Ufficiale n. 47 (Suppl. Ordinario n. 54). [10] EN 1998-3:2005. Eurocode 8- Design of Structures for Earthquake Resistance. Part 3: Assessment and Retrofitting of Buildings.

[11] D'Ayala D., Paganoni, S. (2010). Assessment and Analysis of Damage in L'Aquila Historic City Centre after 6th April 2009. Bulletin of Earthquake Engineering, 9(1):81-104.

[12] Wilkinson, S., Grant, D., Williams, E., Paganoni, S., Fraser, S., Mason, A., Boon, D., Free, M. (2013)

Observations and Implications of Damage from the Magnitude Mw 6.3 Christchurch, New Zealand, Earthquake of 22 February 2011. Bulleting of Earthquake Engineering, 11:107-140.

[13] EN 1881:2006 - Products and Systems for the Protection and Repair of Concrete Structures - Test Methods - Testing of Anchoring Products by Pull-Out Method.

[14] EN 846-2:2000 - Methods of Test for Ancillary Components for Masonry, Part 2: Determination of Bond Strength of Prefabricated Bed Joint Reinforcement in Mortar Joints, 2000.

[15] CINTEC International Ltd. http://www.cintec.com/cintec/anchoring-reinforcement-home.php

[16] BOCA (1993).Basic National Building Code. Building Officials \& Code Administrators International.

[17] EN 772:2000 - Methods of Test for Masonry Units, 2000.

[18] EN 1015:1999 - Methods of Test for Mortar for Masonry, 1999.

[19] EN 1052:1999 - Methods of Test for Masonry, 1999.

[20] Circolare 02/02/2009 n. 617 (2009) Ministero delle Infrastrutture e dei Trasporti - Istruzioni per

l'applicazione delle Nuove norme tecniche per le costruzioni di cui al decreto ministeriale 14 gennaio 2008 (Suppl. Ordinario n.27).Gazzetta Ufficiale 26/02/2009 n. 47.

[21] FEMA 356 (2000).Prestandard and Commentary for the Seismic Rehabilitation of Buildings. ASCE, Washington, USA.

[22] DD CEN/TS 1992:2009 (2009) Design of Fastenings for Use in Concrete.

[23] EOTA European Organization for Technical Approvals (2006). ETAG 001 - Guideline for European Technical Approval of Metal Anchors for Use in Concrete. Amended November 2006.

[24] Subramanian N., Cook R.A. (2004). Behaviour of Grouted Anchors. The Indian Concrete Journal, 78: 2533.

[25] Cook R.A., Eligenhausen R., Appl J.J. (2007). Overview: Behaviour of Adhesive Bond Anchors. Beton und Stahlbetonbau. Supplement: Structural Concrete Special Edition 2007: Anchorage to Concrete, 102(Suppl. 2):16-21.

[26] Cook R.A. (1993). Behaviour of Chemically Bonded Anchors. Journal of Structural Engineering, 119(9):2744-2762.

[27] Zhou, Z., Walker, P., D’Ayala, D. (2008). Strength Characteristics of Hydraulic Lime Mortared Brickwork. Proc. of the Institution of Civil Engineering - Construction Materials, 161(4):139-146.

[28] EN 1996-1-1: 2005. Eurocode 6 - Design of Masonry Structures, 2005.

[29] Malvar L.J. (1991). Bond of Reinforcement under Controlled Confinement. Naval Civil Engineering Laboratory technical note.http://www.dtic.mil/cgi-

bin/GetTRDoc?Location=U2\&doc=GetTRDoc.pdf\&AD=ADA240142 (last accessed 12/04/13).

[30] Pluijm, van der R. (1997). Non-Linear Behaviour of Masonry under Tension. HERON, 42(1): 25-54. 
[31] D’Ayala, D., Paganoni, S. (2013).Protocol for Testing and Design of Dissipative Anchor Devices. In print for Structures and Buildings.

[32] D'Ayala D., Ansal A., (2012). Non-Linear Push-Over Assessment of Heritage Buildings in Istanbul to Define Seismic Risk. Bulletin of Earthquake Engineering, 10 (1): 285-306.

[33] Lowes L. N. (1999).Finite Element Modelling of Reinforced Concrete Beam-Column Bridge Connections. Ph.D. dissertation, University of Berkeley, California, USA.

http://faculty.washington.edu/lowes/dissertation/dissertation.htm (last accessed on 28/06/13). 